\title{
Práticas de discriminação às pessoas em situação de rua: histórias de vergonha, de humilhação e de violência em Fortaleza, Brasil
}

\section{Practices of discrimination against people in street situation: stories of shame, humiliation and violence in Fortaleza, Brazil}

\author{
James F. Moura Jra ${ }^{\mathrm{a}}$, Verônica M. Ximenes ${ }^{\mathrm{b}}$ y Jorge C. Sarriera ${ }^{\mathrm{a}}$ \\ ${ }^{a}$ Universidade Federal do Rio Grande do Sul, Porto Alegre, Brasil ${ }^{\mathrm{b}}$ Universidade Federal do Ceará, Fortaleza, Brasil
}

\begin{abstract}
Resumo
Objetiva-se analisar as práticas discriminatórias e suas consequências experienciadas por pessoas em situação de rua de Fortaleza-Brasil. A pesquisa é qualitativa, com utilização de observação participante e diários de campo em situações ocorridas nos serviços sociais pesquisados da Prefeitura de Fortaleza. Usam-se também Entrevistas Narrativas com quatro pessoas em situação de rua (três homens e uma mulher) usuárias desses serviços. É utilizada como análise a temática narrativa. Identifica-se que as pessoas em situação de rua são discriminadas como violentas, criminosas e usuárias de droga, ocorrendo igualmente nos serviços investigados. Então, os participantes sentem-se agredidos, humilhados e envergonhados, podendo agir violentamente, criativamente e solidariamente como forma de enfrentar essas práticas de opressão. É importante desenvolver ações transformadoras na sociedade e nos serviços sociais voltados para esse público.
\end{abstract}

Palavras chave: situação de rua, discriminação, vergonha, humilhação.

\begin{abstract}
It aims to analyze the discriminatory practices and their consequences experienced by people in the streets of Fortaleza, Brazil. The research is qualitative, using participant observation and field diaries in situations that occur in searched social services of the Fortaleza's Prefectural. It is also used Narratives Interviews with four people in street situation (three men and one woman), users of these services. It is utilized, as analysis, the thematic narrative. It identifies the people in street situation are discriminated as violent, criminal and drug users, occurring likewise in the investigated services. Then, the participants feel beaten, humiliated and ashamed, being able to act violently, creatively, jointly and severally as a way to confront these practices of oppression. Must develop transformative actions in society and social services linked this audience.
\end{abstract}

Keywords: street situation, discrimination, shame, humiliation.

Agradece-se a Coordenação de Aperfeiçoamento de Pessoal de Nível Superior (CAPES) pelo financiamento nos anos 2010-2011-2013. Contacto: J. Moura Jr., Rua Ramiro Barcelos, 2600, Sala 122, Santa Cecília, Porto Alegre-RS, CEP: 90035-003. jamesferreirajr@gmail.com Cómo citar este artículo:

Moura Jr., J. F., Ximenes, V. M. y Sarriera, J. C. (2013). Práticas de discriminação às pessoas em situação de rua: histórias de vergonha, de humilhação e de violência em Fortaleza, Brasil. Revista de Psicología, 22(2), 18-28. doi: 10.5354/0719-0581.2013.30850 


\section{Introdução}

As pessoas em situação de rua geralmente são alvos de práticas discriminatórias, classificando e constituindo de forma depreciativa e opressora as vidas desses indivíduos. O estigma é a representação desse processo de marginalização, fornecendo à pessoa que o porta um reconhecimento perverso de inferioridade frente aos demais. Essa concepção de inferior pode funcionar como justificativa para as práticas estigmatizadoras e para as agressões às pessoas em situação de rua, pois a realidade desses indivíduos, segundo Rosa, Secco e Brêtas (2006), é eminentemente constituída por discriminação e violência. A discriminação na figura do preconceito tem como objetivo a manutenção da ordem social a partir da atribuição a determinados grupamentos de características de periculosidade e de perversidade. Assim, este artigo tem como objetivo analisar as práticas discriminatórias e suas consequências experienciadas por pessoas em situação de rua da cidade de Fortaleza, localizada no Brasil.

Para contextualizar a situação de rua brasileira, utiliza-se os dados de uma pesquisa realizada pelo Ministério do Desenvolvimento Social e Combate à Fome (MDS) do Governo Federal do Brasil que realizou o I Censo e Pesquisa Nacional sobre População em Situação de Rua em 71 das maiores cidades do território tupiniquim. Esta investigação teve como objetivo quantificar e descrever o modo de vida dessa população (Veiga, Quiroga, Novo y Pereira, 2009). Foram consultados, no período de outubro de 2007 a janeiro de 2008, 31.922 pessoas adultas em situação de rua dessas cidades pesquisadas. Segundo Sposati (2009), a realização desse censo é uma importante ação voltada para o reconhecimento dessa população e constrói as bases para compreensão de sua identidade social.

Em relação ao modo de uso da cidade pelas pessoas em situação de rua do I Censo, eles se deslocam, na maioria das vezes, na própria cidade, pois somente $11.6 \%$ das pessoas entrevistadas apresentam mobilidade entre cidades distantes. O contingente de $76.1 \%$ residia na própria cidade ou em localidades próximas do atual espaço utilizado em situação de rua. Sobre o tempo de utilização do espaço público como morada, $48.4 \%$ estão há mais de dois anos dormindo na rua ou em albergues. Os principais motivos citados pelos entrevistados para a ida à rua foram "problemas de alcoolismo e/ ou drogas (35.5\%); desemprego (29.8\%); e desavenças com pai/mãe/irmãos (29.1\%). Dos entrevistados, $71.3 \%$ citaram pelo menos um desses três motivos" (Ministério de Desenvolvimento Social e Combate à Fome, 2009, p. 87). Dentre as pessoas pesquisadas, $82 \%$ são do sexo masculino. A partir desse contexto, a situação de rua reflete a ocupação de pessoas em vias públicas, acarretando, geralmente, uma relação conflituosa com a díade público-privado. Segundo Silveira (2009), as pessoas em situação de rua percebem o espaço público como seu espaço privado de moradia. Com isso, o fato de residirem nesses espaços públicos gera olhares e atitudes de discriminação por estarem constantemente visíveis à população em geral (Rosa, Secco y Brêtas, 2006). Identifica-se que essas práticas discriminatórias são causadas em virtude da existência de estigmas que, segundo Goffman (1963/2008), são marcas ou impressões que indicam degradação e depreciação das pessoas que o portam. "Os gregos que tinham bastante conhecimento de recursos visuais, criaram o termo estigma para se referirem a sinais corporais com os quais se procurava evidenciar alguma coisa de extraordinário ou mau sobre o status moral de quem os apresentava" (Goffman, 1963/2008, p. 11).

Dessa maneira, o estigma é constituído de símbolos. Esses símbolos estão presentes nas formas como as pessoas estão reconhecidas, como também em materiais concretos e em aspectos corporais. No caso das pessoas em situação de rua, esses signos poderiam ser representados pela pele desgastada, pela sujeira no corpo, pelas sacolas carregadas, pelo cheiro de suor, pelas doenças, pela loucura e pelo espaço público como morada. Para Goffman (1963/2008), os símbolos do estigma variam em relação ao grau de visibilidade e capacidade de reconhecimento desses símbolos pela audiência. $\mathrm{O}$ reconhecimento do estigma anula as outras formas de representação de si, como La Taille (2002a, 2002b) concebe os aspectos referentes à constituição identitária, depreciando a boa imagem que o indivíduo busca e tem de si. De acordo com uma revisão sistemática feita por Soares, Nery, Silveira, Noto e Ronzani (2013), o estigma tem impactos negativos no bem estar psicológicos dos indivíduos, podendo levar ao baixo rendimento no trabalho, isolamento e sentimentos de inferioridade e autodepreciaçao.

Assim, a estigmatização funciona como uma prática de opressão. De acordo com Prilleltensky (2008), essas práticas podem desenvolver experiências de insegurança, de exploração, de privação de direitos, de depreciação cultural e de exclusão. Pode-se considerar que as pessoas em situação de rua são alvos dessas práticas de opressão, constituindo suas identidades de forma específica e opressora. Sobre essas práticas discriminatórias, de acordo novamente com os resultados da pesquisa realizada pelo Ministério de Desenvolvimento Social e Combate à Fome (2009), as pessoas em situação de rua são impedidas de acessar os serviços de saúde (18.4\%), os transportes coletivos (29.8\%), os shopping centers (31.3\%), os estabelecimentos comerciais (31.8\%) e os órgãos públicos (21.7\%). Muggleton (2013), em uma pesquisa sobre livrarias públicas, também identifica que esses espaços não são utilizados pelas pessoas em situação de rua 
por conta do preconceito. Dessa maneira, mesmo que esses locais sejam para serem usados por qualquer pessoa, há uma política silenciosa que discrimina e impede as pessoas em situação de rua de fazer uso desses locais.

A explicação desse panorama de impedições pode estar na pesquisa realizada na cidade de Fortaleza em 2012 com pessoas em situação de rua. Esses indivíduos foram identificados como portadores de duas identidades sociais alvos de estigmatizações: a identidade social de pobre e a identidade social de morador de rua. A identidade social de pobre está igualmente permeda por uma perspectiva depreciativa e enfraquecedora das potencialidades (Cidade, Moura Jr. y Ximenes, 2012). Identifica-se que essa identidade está baseada nos papéis sociais de conformado, de crente em Deus como responsável por tudo, de mártir, de vagabundo, de causador das mazelas sociais, de sujo, de doente e de culpado pela situação de pobreza. No entanto, apesar das pessoas em situação de rua estarem imersas em uma situação de extrema pobreza, elas são preponderantemente reconhecidas a partir da identidade social de morador de rua com os papéis sociais de drogado, de criminoso, de violento, de sujo e de doente. Observa-se que esse reconhecimento é mais agressivo, evidenciando de forma opressora esse processo de discriminação às pessoas em situação de rua (Moura Jr., 2012).

Segundo Goffman (1963/2008), o estigma pode acarretar o sentimento de vergonha e de humilhação. Esta é considerada de difícil acesso, porque sua constatação é complicada de ser comprovada, como também o desejo da vítima de humilhação é esconder essa experiência devido à vergonha em expressá-la. A humilhação, então, seria a situação de desrespeito com o indivíduo, pois o oposto a uma atitude respeitosa é uma atitude de humilhação nas suas mais diversas formas (Alencar y La Taille, 2007). Corroborando com essas considerações, a humilhação seria uma situação em que o indivíduo tem retirado seu poder de escolha a partir de um tratamento com desrespeito de uma pessoa ou de um grupamento realizado de forma pública, sendo abordado como um ser humano em um patamar inferior (Lukes, 1997; Schick, 1997). Essa atitude discriminatória caracteriza-se por uma prática de violência não legítima de rebaixamento impetrada por outrem (La Taille, 2002a, 2009). Pode ser desenvolvida também a partir de uma situação que exponha a vergonha ou culpabilize o indivíduo. Sobre as consequências da humilhação na vítima, as práticas humilhantes destroem o autorrespeito do indivíduo humilhado, enfraquecendo igualmente o respeito que este último também poderia ter com outras pessoas e podendo desenvolver, assim, um ciclo opressor e vicioso de práticas de humilhação.
A humilhação igualmente pode gerar a vergonha, mas a diferença existente entre esses sentimentos é que a pessoa envergonhada compartilha a imagem negativa imposta, enquanto que a pessoa humilhada geralmente não aceita essa imposição, apesar de legitimar o humilhador. No entanto, quando ocorre o compartilhamento do juízo depreciativo pela vítima humilhada, há a vergonha e a humilhação somadas (La Taille, 2002a). Apesar dessa diferença, Zavaleta (2007) denota que a vergonha e a humilhação estão relacionadas a aspectos interacionais permeados por posições assimétricas de poder. A vergonha depreciativa existe pelo fato da pessoa ser algo em sociedade dependendo da sua raça, da sua classe social e da forma como é reconhecida socialmente, sendo um sentimento central para compreensão do ser humano de uma forma abrangente e geral (La Taille, 1996, 2002a). Claesson e Sohlberg (2002), Averilla, Diefenbachb, Stanleyb, Breckenridgea, e Lusbya (2002) e La Taille (2007) expõem que a vergonha se refere a um significativo sofrimento psicológico, repercutindo em atitudes de isolamento social, de impotência e de incapacidade, podendo desenvolver fobia social e ideações suicidas. Segundo La Taille (1996), a vergonha está relacionada ao sentimento de exposição, ou seja, de ser objeto do olhar dos outros.

Assim, além das condições estruturais relacionadas à situação de rua, as pessoas inseridas nessa realidade vivenciam uma variedade de situações opressoras. Essa adversidade concreta, segundo Rosa, Secco e Brêtas (2006), torna-se ainda mais profunda, pois as pessoas em situação de rua são alvos de constantes atitudes de discriminação e de violência. Além disso, há uma atitude generalizada de indiferença contra esses indivíduos. O fenômeno da rua é naturalizado, concebido como permanente e ahistórico, marginalizando os indivíduos que estão nessa situação (Mattos y Ferreira, 2004). Então, como forma de desvelar essa realidade opressora, tem-se como objetivo analisar as práticas discriminatórias e suas consequências experienciadas por pessoas em situação de rua da cidade de Fortaleza.

\section{Método}

A legitimidade desta pesquisa é baseada na apresentação clara e rigorosa do seu processo de realização (Montero, 2006). Compreende-se o fazer pesquisa constituído de um caráter político e ético. Esse processo investigativo é uma obra coletiva em que se assume uma vinculação com as pessoas envolvidas na construção do processo artesanal que é a pesquisa, reconhecendo-os, segundo Montero (2006), como produtores de conhecimento e de ações. Esta pesquisa, então, segue as diretrizes que regem a Resolução 196, de 10 de outubro 
de 1996, do Conselho Nacional de Saúde do Governo Federal do Brasil. Como encaminhamento dos rigores ético, a pesquisa foi aprovada no Comitê de Ética da Pesquisa da Universidade Federal do Ceará com o número do protocolo 016/11.

Argilaga (1995) afirma que o corpus da pesquisa vai sendo construído à medida que o pesquisador aproxima-se do fenômeno estipulado, no caso, a situação de rua. Assim, o local de realização da pesquisa foi a cidade de Fortaleza, localizada no Estado do Ceará-Brasil. A população fortalezense está estimada em 2.452.185 habitantes (Instituto Brasileiro de Geografia e Estatísticas, 2010). O número de pessoas em situação de rua na cidade aproxima-se de 3000 , segundo dados da Secretária Municipal de Assistência Social (Semas) da Prefeitura Municipal de Fortaleza (Girão, 2010). Com fins de realização desta pesquisa, a Semas foi escolhida como instituição parceira dessa investigação por uma ordem prática e política a partir da inserção no Abrigo Provisório para pessoas em situação de rua da cidade de Fortaleza e no Centro de Referência Especializado da Assistência Social para população de rua (Creas-pop). Esses equipamentos sociais estão situados na esfera pública de nível regional com serviços que maior abrangiam a população em situação de rua, tendo o compromisso de estarem voltados para as intervenções com foco na melhoria da qualidade de vida desses indivíduos. Dessa forma, as devolutivas desse trabalho de pesquisa puderam também ter um impacto maior na vida cotidiana das pessoas através de aperfeiçoamentos desses serviços.

\section{Participantes}

Há a necessidade de construção de critérios bem definidos para os participantes, pois, segundo Flick (2009), a construção desses critérios tem como objetivo encontrar os casos mais comuns para estudar um determinado fenômeno. Foram utilizados os seguintes critérios de escolha dos participantes da pesquisa: morar pelo menos três anos na rua; não possuir algum vínculo empregatício formal; e ser adulto para se autorizar a partir da assinatura do termo de consentimento livre e esclarecido. Com esses critérios, foi realizada uma seleção de participantes por conveniência e por saturação de acordo com Marshall (1996), abrangendo quatro pessoas que aceitaram realizar a entrevista narrativa. Foram, então, fornecidos nomes fictícios a cada um. Andreza é solteira; tem 34 anos; tem um filho, estando há 3 anos e 6 meses na rua. Mario é solteiro; tem 49 anos; não tem filhos, estando a mais de três anos na rua. Alberto é solteiro, paraplégico; tem 37 anos; tem 3 filhos, estando há 29 anos na rua. Francisco é solteiro; tem 23 anos; tem uma filha, estando há 4 anos na rua. As outras situações com relatos apresentadas foram desenvolvidas a partir de observação participante de pessoas em situação de rua que estavam nos equipamentos sociais participantes dessa investigação.

\section{Técnicas de coleta de dados}

Primeiramente, foi utilizada a observação participante a partir de visitas semanais em diferentes turnos nos equipamentos sociais pesquisados durante os seis meses de realização da pesquisa de campo. Esta é uma técnica metodológica em que o pesquisador assume uma postura comportamental de dispor-se a estar imerso em uma realidade específica tentando compreender e aproximar-se dos sujeitos em questão (Angrosino, 2009; Argilaga, 1995; Haguette, 1987/2005). É utilizada para entender as ações dos atores da pesquisa em seu contexto natural a partir do contato direito do pesquisador com eles. Uma técnica auxiliar para realização da observação participante foi o diário de campo (DC), que é utilizado na antropologia, sociologia e, posteriormente, na Psicologia Social (Montero, 2006). Segundo Angrosino (2009), a elaboração dos diários de campo sistemáticos tem como premissa o registro de detalhes sem preconceitos, encontrando fatores que possam ser encarados como padrões. Assim, tem-se como fim a explicação da situação e a descrição do cenário físico, dos comportamentos e das interações dos participantes. Quando um trecho dos diários de campo das observações participantes é utilizado, usa-se a sigla DC, a data da realização daquela observação e a página daquele trecho no documento original.

Assim, a partir do fortalecimento dos vínculos e do contato direito cotidiano com algumas pessoas em situação de rua, foram realizadas Entrevistas Narrativas (EN) Biográficas com três meses de observação participante. Segundo Jovchelovitch e Bauer (2002), dadas as suas características (liberdade do informante, dados sob formato de história e não pergunta-resposta no momento de elaboração da história de vida pelo participante), essa técnica apresenta a vantagem de apreender os fatos sob perspectiva do entrevistado, isto é, de forma situada ou contextualizada. Neste artigo, quando um trecho de uma entrevista narrativa é apresentado, indicamos as siglas EN, o nome do entrevistado e a páginas referentes aquele trecho no arquivo original da transcrição.

\section{Análise dos dados}

O foco da análise é o conteúdo encontrado tanto nos diários de campo, como nas entrevistas narrativas. Utiliza-se a análise narrativa temática, em que, segundo Riessman (2008), os sentidos produzidos em pesquisa são teorizados a partir da criação de categorias em que as histórias de vida e os diários de campo ultrapassam o nível individual, possibilitando a criação de características referentes a grupamentos coletivos. Para criação dessas categorias e realização da análise temática, foi utilizado o software Atlas.ti 5.2 de análise qualitativa de dados. Segundo Gibbs (2009), o uso desta ferramenta facilita a realização da análise, pois permite os registros do processo de construção da análise e o acesso fácil e prático dos sentidos elaborados na pesquisa. 


\section{Resultados e discussão}

Práticas de discriminação impetradas às pessoas em situação de rua

A discriminação é desenvolvida a partir do reconhecimento de símbolos do estigma (Goffman, 1963/2008). Francisco fala de como esses símbolos do estigma repercutem na forma como é reconhecido: "As pessoas olham para o cara e veem o cara como um nada. Só vê um vagabundo, fedido, ladrão. Por mais que ele não roube, mas ele tem aquela figura sofrida que a droga faz com o sujeito" (Entrevista Narrativa, EN Francisco, p.14). Uma usuária do Abrigo Provisório também compreende que na rua é reconhecida dessa maneira, apontando que está sendo percebida de forma diferente nesse equipamento social: "estava gostando de ficar no abrigo, pois está recebendo ajuda. Diferente de uma vivência de rua em que se sente estigmatizada, pois percebe que os outros nem olham para ela e que ninguém quer ajudá-la” (Diário de Campo, DC 7, 16/03/11, p. 10).

Analisa-se, assim, que esses símbolos do estigma permeiam a realidade das pessoas em situação de rua, como também seu psiquismo. Santos, Koller, Pilz, Dias e Wagner (2006) afirmam que essas práticas são corriqueiras no cotidiano das pessoas em situação de rua. Uma das educadoras sociais traça uma consideração depreciativa acerca dos usuários do Abrigo Provisório, afirmando que as pessoas em situação de rua são somente usuárias de drogas (DC 7, 16/03/11, p. 11). Essa mesma discriminação voltada para a reprodução dessa compreensão de usuário de drogas ocorre também com os profissionais do Centro de Referência Especializado da Assistência Social para população de rua (Creas-pop). Eles afirmam que o dinheiro fornecido pelo Programa Bolsa Família ${ }^{1}$ é unicamente utilizado para a compra de droga (DC 10, 22/03/11). Esmeraldo Filho (2006) afirma que uma das principais formas de discriminação às pessoas em situação de rua está relacionada a compreensão estigmatizada desses indivíduos unicamente como usuários de drogas.

Outra forma de reconhecimento depreciativa seria relacionado a figura do criminoso. Alguns participantes da pesquisa que utilizavam o Creas-pop são percebidos somente como criminosos. Eles identificam que muitas pessoas em situação de rua cometem crimes, mas concebem que há uma compreensão generalizada da sociedade acerca da visão das pessoas em situação de rua como criminosas (DC 15, 06/04/11). Segundo um dos profissionais do Abrigo Provisório, eles já receberam vários telefonemas de uma delegacia de polícia próxima reclamando que a instituição estava acolhendo criminosos (DC 24, 06/05/11). Sobre essa forma de reconhecimento perverso, um usuário do Creas-pop comenta que:
Há muitos moradores de rua que não são criminosos. Ele afirma que a maioria das pessoas não pensam dessa maneira, porque, muitas vezes, ele está caminhando na rua e nota as pessoas mudarem de calçada ou ficarem amedrontadas com a presença dele. Ele diz se sentir discriminado, pois não é ladrão (DC 15, 06/04/11, pp. 30-31).

Esse fenômeno também parece acontecer quando se sente medo de qualquer pessoa em situação de rua, como afirma um usuário do Creas-pop (DC 15, 06/04/11). Ele fala da mudança de local desse equipamento social como tentativa de resguardar os profissionais de possíveis pessoas em situação de rua que são criminosas. Sente-se indignado com isso, porque parece que se percebe reconhecido de uma forma com que não pactua. Uma das usuárias do Abrigo preocupase também com a compreensão da pessoa em situação de rua como violenta de uma forma generalizada (DC 7, 16/03/11). Ela se incomoda com o reconhecimento das pessoas em situação de rua como agressivas, porque percebe que muitos de seus pares não desempenham atitudes violentas.

Prova da generalização desse reconhecimento está na observação de uma profissional do abrigo que percebe as pessoas em situação de rua como perigosas: "Ela fala que as pessoas que estão no Abrigo são muito perigosas. Estão calmas, porque querem ganhar a casa própria oferecida pela prefeitura" (DC 8, 18/03/11, p. 16). Segundo Esmeraldo Filho (2006), as pessoas em situação de rua são confundidas com pessoas violentas, traficantes e assaltantes, demonstrando, assim, uma característica de criminalização do indivíduo. Dessa maneira, um dos usuários do Abrigo Provisório denota que isso faz com que as pessoas não percebam que os indivíduos em situação de rua são talentosos (DC 16, 20/04/11). Com isso, compreende que faltam muitas oportunidades para as pessoas em situação de rua por conta desse olhar opaco às potencialidades. Mattos e Ferreira (2004) entendem que isso ocorre, porque há uma atitude de indiferença da sociedade frente às pessoas em situação de rua, tornando essa realidade natural.

Analisa-se que essa forma cega de compreender o indivíduo constitui o reconhecimento depreciativo das pessoas em situação de rua como inferiores. Schick (1997) afirma que os processos de humilhação partem dessa compreensão de que alguns seres humanos são reconhecidos como subhumanos. Essa forma de compreensão inferior ocorre até na maneira como que o próprio governo municipal presta atenção às

\footnotetext{
${ }^{1}$ É um programa de transferência de renda para pessoas em situação de pobreza desenvolvido pelo Governo Federal do Brasil.
} 
pessoas em situação de rua. Alguns usuários se sentem mal tratados, pois receberam da Prefeitura de Fortaleza materiais de higiene vencidos (DC 16, 20/04/11). Uma das usuárias mostrou que suas mãos e seus pés estavam repletos de feridas. Ela disse que elas tinham aparecido depois do uso desses materiais de higiene. Também pode ser examinado esse reconhecimento perverso da compreensão da pessoa em situação de rua como inferior, de criminoso e de causador de mazelas sociais em outra situação. O pesquisador ajudava um usuário do abrigo que havia sido desligado desse equipamento social no preparo de sua comida no canteiro central de uma grande avenida de Fortaleza, próxima ao Abrigo Provisório. Enquanto se prestava auxílio junto com os outros abrigados, "via-se as pessoas olhando para nós. Percebia-se o olhar de repulsa e de estranheza voltado para aquela situação. Parecia que estávamos fazendo alguma coisa errada na dinâmica da cidade" (DC 28, 18/05/11, p. 54)

Essa discriminação também permeia a dimensão espacial. Santos (2009) afirma que "a discriminação contra o corpo, a aparência física, a forma de se vestir e os comportamentos dessa população também se estenderam aos espaços onde ela se localiza" (p. 140). Continuando com essa última autora, o próprio processo de desenvolvimento das cidades permeado pelo capitalismo e pelo neoliberalismo desenvolvem uma tendência punitiva, higienista e repressiva às pessoas em situação de rua, escondendo-as, punindo-as, segregando-as, exterminando-as com o objetivo de construir uma "imagem positiva" da cidade. Mattos e Ferreira (2004) acrescentam nessa compreensão uma perspectiva de distanciamento da sociedade desse fenômeno. Compreende-se, assim, a diversidade de práticas de discriminação realizadas às pessoas em situação de rua na cidade de Fortaleza. Pretende-se, então, abordar as possíveis consequências dessas práticas.

As consequências das práticas de discriminação: a vergonha, a humilhação e a violência

As práticas discriminatórias podem fazer as pessoas serem humilhadas e se sentirem envergonhadas, pois igualmente se percebem portando estigmas depreciadores. Zavaleta (2007) afirma que as pessoas envergonhadas e humilhadas passam a não ter coragem de estar em determinados espaços públicos, de adentrar em órgãos do governo e de solicitar seus direitos. Contribuindo com essas considerações, Alkire (2007) afirma que a pessoa, ao se sentir humilhada e envergonhada, tem impedida a sua capacidade de agenciamento. Isso ocorre, porque, segundo Zavaleta (2007), a vergonha traz a vontade de se esconder e de fugir. O indivíduo sente sua estima devastada a partir de uma avaliação pessoal negativa. É uma experiência dolorida e global de sentir-se inferior, menor e sem poder. Mario, em seu relato, apresenta algumas dessas características da vergonha a partir de experiências proporcionadas pela situação de rua, afirmando seu constrangimento perante elas.

Outra coisa que é constrangedor, cara. Você tá na fila aí a galera vem bater foto. Você tá até infringindo, porque tem que pedir permissão. [...] Outra coisa que é também muito chato: você receber roupa. Sábado e final de semana também tem o batgut ${ }^{2}$ que é bastante constrangedor. Você chegar e ficar. No caso da dormida, cara, você acorda de manhã e tem um bocado de gente olhando. Você ir atrás de comida. Para ter alimentação, você precisar participar de não sei o quê, não sei o quê. Eu não to falando que é ruim, mas é bom para a galera ocupara mente, mas é meio constrangedor, né cara? Você comer a comida sempre no mesmo prato, no pratinho de plástico com a colherzinha de plástico também (E. Mario, p. 16).

Mario apresenta sua vergonha relacionada significativamente ao olhar das outras pessoas e às situações que percebe como sendo indignas. La Taille (2002a) explana acerca dessas características da vergonha. Segundo esse autor, o envergonhar-se está relacionado ao fato de ser objeto do olhar de uma audiência, como também de legitimar um juízo depreciativo. Essas situações também são apresentadas por Alberto:

E outros momentos difíceis também é agora o que eu to enfrentando com a minha filha, porque eu to todo errado. Como é que eu vou vê ela? Ela tá lá no Genibaú, eu tava fazendo visita a ela, eu tava tudo direitinho. De repentemente desandou tudo, porque você tá na rua... Eles (a família) me vê diferente mermo. A gente vê, às vezes eles num fala, mas a gente vê a diferença. Eu aprendi tanto a lidar com o por dentro assim da pessoa. Às vezes, as pessoas me machuca só da forma de olhar pra mim, sabe? Aí eu vejo que o abandono é assim. Essa parte também que eu fico muito triste e é isso (EN Alberto, p. 47).

Alberto se percebe como estando "errado", pois compreende, a partir do reconhecimento dos outros, que as pessoas em situação de rua são fracassadas, confirmando as considerações de La Taille (2002a). Outro fator que constitui o cenário de discriminação é a humilhação. Zavaleta (2007) concebe que a humilhação pode ser tanto um sentimento interno, como uma ação externa (ser humilhado por alguém). Geralmente, ela está relacionada a algum ato. No entanto, diferente da

\footnotetext{
${ }^{2}$ Iogurte doado por algumas entidades filantrópicas as pessoas em situação de rua periodicamente na cidade de Fortaleza.
} 
vergonha, a humilhação tem caráter interacional desenvolvendo-se quando há disparidade de poderes. Mario se sente humilhado por um educador social. Esse participante percebe o profissional como querendo ser mais importante do que os outros, sentindo raiva por isso.

Aqui na merenda, tem educadores aqui que especificamente eu não gosto, porque, sabe, é um cara altamente chato, cara altamente, sabe? Ele foi tão idiota de uma certa forma, tão inconsequente que todo mundo disse. Ele vai lá dentro e pega o pão e vai merendar lá na frente de todo mundo só para dizer que tá comendo pão. Eu olhei assim para ele. Chega ele baixou assim a cabeça. [...] É uma violência psicológica, cara. É pior que se ele tivesse me dado um murro, cara. Que aí, pelo menos, eu ia saber tomar outra atitude. Que eu acho que tá faltando palavra par explicar (EN Mario, p. 16 e p. 17).

Observa-se, assim, o significativo sofrimento de Mario quando compara essa situação de humilhação com um soco, estipulando que a situação humilhante traz mais sofrimento. Além disso, esse cenário de discriminação infelizmente pode relacionar-se com os dispositivos governamentais voltados para a população em situação de rua. Em vez de ser um espaço de acolhimento, pode tornar-se mais um reduto de práticas de opressão às pessoas em situação de rua. Assim, um usuário do Creas-pop afirma que:

[...] sentiu-se indignado, porque, quando foi atendido, ele foi tratado de uma maneira ignorante, segundo ele. A profissional disse que não o encaminharia, porque não tinha vaga para o Espaço. No entanto, ela foi muito ríspida com ele. Então, ele se sentiu humilhado, falando que "só porque nós somos moradores de rua, as pessoas pensam que não podem tratar bem a gente" (DC 15, 06/04/11, p. 31)

Assim, examina-se que essas experiências vivenciadas pelos entrevistados foram muito impactantes para si, gerando um forte sentimento de indignação e revolta. De acordo com Zavaleta (2007), analisa-se que a experiência de sentir-se humilhado representa a diminuição ou a depreciação do orgulho e da dignidade do indivíduo, geralmente, gerando raiva e sentimento de vingança, pois a pessoa se percebe sendo desvalorizada, ridicularizada ou injustamente degradada. La Taille (2009) concebe que, diferente da vergonha, na humilhação o indivíduo geralmente não concorda com o juízo depreciativo da prática humilhante, podendo atuar contra essa situação.

Igualmente, identifica-se que a discriminação social às pessoas em situação de rua está intimamente relacionada às práticas de violência física. Assim, junto com a vergonha e a humilhação, a violência também pode ser entendida como uma consequência da discriminação social. De acordo com Moura Jr. (2012), isso ocorre, porque as pessoas em situação de rua são reconhecidas como inferiores, como se não tivessem que ser respeitadas e podendo receber os mais perversos tipos de tratamento em virtude de não localizar-se no mesmo patamar do autor da prática discriminatória. De acordo com Silva Filho (2002), a violência policial é taxada como um dos principais problemas da situação de rua. Segundo usuários do Creas-pop, os policiais são os principais autores de casos de agressão às pessoas em situação de rua, que são percebidas somente como drogadas e criminosas (DC 20, 27/04/11).

Também são autores dessas agressões vigilantes particulares e qualquer pessoa disposta a violentar as pessoas em situação de rua. É remetido um clima de violência a uma vivência de rua, construindo uma atmosfera de constante insegurança (Esmeraldo Filho, 2010). Alguns usuários do Creas-pop reforçam essa afirmação, concebendo que o clima de medo impera na situação de rua. Eles têm muita dificuldade para dormir, porque se sentem muito inseguros (DC 20, 27/04/11). Francisco fala que sofreu várias agressões quando estava em situação de rua, conformando-se e buscando encontrar fatores positivos nessas situações: "Sem contar que antes de eu ir para cadeia, sofri vários, sofri vários atentados na rua. E dos atentados eu levei um tiro de raspão no meu rosto. Para mim foi um grande livramento que eu tive na minha vida" (EN Francisco, p. 13).

Andreza, igualmente, vivencia esse cenário de violência e de insegurança: "Eu ultimamente aqui dentro de Fortaleza já levei muitas consequências. Muitas consequências de pedradas, muitas consequências de físico na rua". (EN Andreza, p. 1). Outros usuários do Creas-pop confirmam essas considerações da companheira de rua, pois admitem que a situação de rua se constitui como espaço de muito perigo, geralmente, estabelecido pelas práticas criminais existentes desenvolvidas pelas próprias pessoas em situação de rua. Dois usuários do Creas-pop afirmam:

que se sentem muito cansados de morarem na rua, porque "você tem que ter olho de gato: um aberto e outro fechado". Segundo eles, a pessoa que está na rua pode ser constantemente vítima de roubos. Quando isso acontece, prejudica os planos almejados, porque, geralmente, os documentos são também levados. Na sala de espera, somente um deles era portador de documentação, pois o restante tinha sido roubado (DC 15, 06/04/11, p. 31-32).

Como consequência dessa violência, na pesquisa realizada pelo Ministério de Desenvolvimento Social e Combate à Fome (2009), 43.8\% manifestaram preferência em dormir em albergues, sendo que $69.3 \%$ desses escolhiam essa al- 
ternativa porque a violência aparecia como principal fator para não dormir na rua. Assim, evidencia-se que a violência permeia a situação de rua, gerando sequelas físicas e psicológicas. De acordo com Esmeraldo Filho (2010), Mattos e Ferreira (2004) e Rosa, Secco e Brêtas (2006), esse cenário de agressões infelizmente é comum às pessoas em situação de rua. Alkire (2007) afirma que a violência, como fator que interfere na segurança física, é uma das principais causas da privação das liberdades humanas em múltiplos parâmetros. No entanto, identifica-se também que, além dessa realidade extremamente adversa, as pessoas em situação de rua podem encontrar estratégias de enfrentamento perante essas dificuldades.

\section{Estratégias de enfrentamento da discriminação}

O indivíduo é, de acordo com Góis (2012), portador de potencialidades que são inerentes a sua constituição humana e ativo no processo de transformação de si e da realidade. A partir dessa compreensão, identificam-se estratégias de enfrentamento a essa realidade de discriminação e de violência, formando algumas alternativas utilizadas pelas pessoas em situação de rua presentes neste estudo. É vislumbrado, assim, que, além das pessoas em situação de rua serem vítimas de agressão, podem igualmente desempenhar ações violentas através da prática do roubo e da agressão como uma estratégia de sobrevivência e de reação. A partir dessa compreensão de uma vivência de rua inserida em um clima de violência, Esmeraldo Filho (2006) afirma que as pessoas em situação de rua podem utilizar essa mesma violência como um mecanismo de proteção pessoal. Neste sentido, a rua é vista por esses indivíduos como um lugar onde não pode existir a fraqueza, pois ser fraco representa para as pessoas em situação de rua uma trajetória de exploração e de agressão.

Nesse sentido, houve uma situação de violência quando dois usuários ficaram na iminência de digladiarem-se com armas brancas no Abrigo Provisório. Foi necessário o auxílio da polícia para impedir o conflito (DC 14. 04/04/11). Mais uma situação de violência em que foi necessária a intervenção policial foi quando um dos usuários estava sob forte efeito de drogas e agrediu com um chute uma das educadoras sociais. Observa-se que as ações violentas podem ser desenvolvidas a partir do uso de substâncias psicoativas. Em um caso ilustrativo dessa relação, houve uma briga entre os usuários. Um deles tinha ameaçado com o vidro quebrado de garrafa sua companheira. Depois desse acontecimento, os outros abrigados afirmaram que a agressividade é comum entre as pessoas em situação de rua. Eles disseram que usualmente as agressões são motivadas pelo uso abusivo de drogas (DC 7, 16/03/11).
Mendes e Machado (2004) reforçam que as pessoas em situação de rua podem ser os algozes de seus pares, reproduzindo a ideologia opressora dominante em atitudes, reconhecimentos e agressões. Góis (2012) igualmente expõe que o oprimido também pode ser constituído de atitudes opressoras, sendo o promotor de violência. Um usuário também defende essa afirmação, concebendo que as pessoas em situação de rua podem ser muito perigosas (DC 24, $06 / 05 / 11)$. No entanto, analisa-se que há também estratégias de enfrentamento positivas e construtivas. Esmeraldo Filho (2010) afirma que há a possibilidade de construção de vínculos afetivos de cooperação e de solidariedade, apesar do constante clima de desconfiança. Na realização da observação participante, foram experienciados esses vínculos de companheirismo entre o pesquisador e as pessoas em situação de rua vendo-as jogar futebol e jogando futebol com elas (DC 17, 20/04/11); participando de suas refeições (DC 8, 18/03/11); e jogando dominó (DC 9, 23/03/11). Além disso, elas afirmavam que sentiam falta do pesquisador quando esse demorava muito tempo a visitá-las no Abrigo Provisório (DC 29, 13/06/11; DC 32, 11/07/11). Há, então, igualmente a possibilidade do exercício do companheirismo entre as pessoas em situação de rua a partir do afeto e da solidariedade.

Identifica-se também que o grupo de pessoas que estava morando em uma das praças da cidade de Fortaleza se percebia como uma família. Francisco afirma que eles eram um grupo singular que passou a "viver em sociedade" (EN Francisco, p. 4). Uma das usuárias do Abrigo Provisório sintetiza sua compreensão sobre os momentos em que residiam na Praça da Bandeira: "Eles ficaram na praça por quase um ano, mas os barracos só foram construídos nos últimos três meses antes da guarda municipal removê-los do espaço. Salienta que, quando estavam na praça, todos conviviam bem. Não havia brigas, nem discussão" (DC 30, 27/06/11, p. 56).

A partir dessa situação, Silva Filho (2002) defende a afirmação de que os vínculos afetivos e as relações de solidariedade são imprescindíveis para a sobrevivência a uma situação de rua. Um dos usuários do Creas-pop tem uma compreensão semelhante, percebendo que há pessoas em situação de rua que constroem vínculos afetivos positivos (DC 15, 06/04/11). Igualmente, identifica-se que a compreensão das pessoas em situação de rua como portadoras de potencialidades são mais eliciadas por esses próprios indivíduos. Um dos usuários do Creas-pop afirma que “todo morador de rua tem um talento, pois os moradores são muito criativos" (DC 15, 06/04/11, p. 31). Assim, além dele se reconhecer como portador de potencialidades, ele considera as pessoas 
em situação de rua como criativas. Este é muitas vezes o estratagema encontrado pelas pessoas em situação de rua para sobreviver nessa realidade tão adversa. Mario percebe a periculosidade da situação de rua como esse espaço de violência e de insegurança. Constata que é necessário criar estratégias de sobrevivência para viver. A o uso da criatividade seria uma dessas possibilidades:

Não, a pessoa na rua encara todo tipo de problema, sabe? O nome já tá dizendo "vulnerabilidade". O cara está exposto a qualquer coisa. Eu já presencie em já estar no local de agressões, mas aí isso aí na minha percepção tem que saber se sair, né? O cara tem que ter o rebolado legal. O cara tem que tá ligado mesmo legal (EN Mario, p. 16).

Alberto tem essa compreensão das pessoas em situação de rua como portadoras de potencialidades e de criatividade. No entanto, ele nota que a sociedade não percebe esses aspectos potenciais (DC 16, 20/04/11). Dessa maneira, as práticas discriminatórias constituem o obscurecimento dessas potencialidades das pessoas em situação de rua. Para Guzzo (2010), a opressão tem um foco psicossocial, violando e fazendo sofrer populações e indivíduos imersos em sua estrutura opressora. Assim, a ética da libertação coloca-se na posição de desvelar essas formas opressoras da sociedade que enfraquecem as potencialidades dos seres humanos. É pautada, então, na construção de conhecimento, segundo Ximenes e Barros (2009), a favor dos oprimidos, baseados em uma postura comprometida ética e politicamente na transformação dessa realidade social opressora.
Conclusão

Evidencia-se que a vergonha, a humilhação e a violência estão interligadas e se relacionam. Pode-se compreender a situação de rua como permeada por estigmas que envergonham e são promotores de humilhação. Essas práticas de humilhação podem estar geralmente envolvidas com atos de agressão física às pessoas em situação, podendo gerar ainda mais vergonha. Constrói-se, então, um ciclo opressor e desumano para os indivíduos que estão na rua. A partir disso, foi examinado que as pessoas em situação de rua igualmente constroem estratégias de enfrentamento dessa realidade. Apontase que o exercício de ações violentas seria uma maneira de combate a essas práticas discriminatórias. Evidencia-se, assim, a necessidade de compreender a situação de rua como uma realidade complexa, em que esses indivíduos podem ser autores de atos infracionais e agressivos, mas também essas ações não devem ser as únicas vias de reconhecimento dessas pessoas.

Critica-se, portanto, o reconhecimento perverso e discriminatório desenvolvido preconceituosamente pelos próprios profissionais dos serviços públicos sociais que deveriam agir numa perspectiva transformadora, pois a maior parte da sociedade já desenvolve cotidianamente discriminação às pessoas em situação de rua. Dessa maneira, salienta-se também a necessidade de serem evidenciadas compreensões mais positivas às pessoas em situação de rua. Observa-se, por fim, que esses indivíduos constroem fortemente vínculos afetivos e usam da criatividade para lidar com essas práticas discriminatórias opressoras. Avalia-se a necessidade de construção e de efetivação de políticas e de ações de fortalecimento das pessoas em situação de rua, porque elas são constantemente vítimas de diversas formas de violência física e simbólica. E é premente também o desenvolvimento dessas políticas por profissionais que não reproduzam essa espiral violadora e estigmatizante às pessoas em situação de rua, mas que estejam implicados em novas formas de constituição societária menos opressora e estigmatizante.

\section{Referências}

Alencar, H. M. e La Taille, Y. (2007). Humilhação: o desrespeito no rebaixamento moral. Arquivos Brasileiros de Psicologia, 59(2), 217-231.

Alkire, S. (2007). The missing dimensions of poverty data: an introduction. OPHI Working paper $n^{\circ}$ 00. Oxford: Oxford Poverty \& Human Development Initiative. Recuperado de http://www.ophi.org.uk/working-paper-number-0/

Angrosino, M. (2009). Etnografia e observação participante. Porto Alegre: Artmed.
Argilaga, M. T. A. (1995). La observación participante. In A. G. Báztan (Ed.), Etnografía: metodología cualitativa e investigación sociocultural (pp. 54-69). Barcelona: Boixareu Universitaria.

Averilla, P. M., Diefenbachb, G. J., Stanleyb, M. A., Breckenridgea, J. K. e Lusbya, B. (2002). Assessment of shame and guilt in a psychiatric sample: a comparison of two measures. Personality and Individual Differences, 32, 1365-1376. doi: 10.1016/S01918869(01)00124-6

Cidade, E. C., Moura Jr, J. F. e Ximenes, V. M. (2012). Implicações psicológicas da vida em condições de pobreza para o povo latino-americano. Psicologia Argumento, 30(68), 87-98. doi: 10.7213/psicol.argum.5886 
Claesson, K. e Sohlberg, S. (2002). Internalized shame and early interactions characterized by indifference, abandonment and rejection: replicated findings. Clinical Psychological Psychotherapy, 9, 277-284. doi: dx.doi.org/10.1002/cpp.331

Esmeraldo Filho, C. E. (2006). Saúde Mental e (ex)-moradores de rua: um estudo a partir do valor e do poder pessoal. (Monografia não publicada de Graduação em Psicologia). Universidade Federal do Ceará, Fortaleza.

Esmeraldo Filho, C. E. (2010). Necessidades de saúde dos moradores de rua: desafios para as políticas sociais do município de Fortaleza-CE. (Dissertação não publicada de Mestrado em Saúde Pública), Universidade Estadual do Ceará, Fortaleza.

Flick, U. (2009). Desenho da pesquisa qualitativa. Porto Alegre: Artmed.

Gibbs, G. (2009). Análise de dados qualitativos. Porto Alegre: Artmed.

Girão, I. (2010). População de rua aumenta 40\%. In Diário do Nordeste. Recuperado de http://diariodonordeste.globo.com/ materia. asp ? codigo $=897893$

Goffman, E. (2008) Estigma: notas sobre a manipulação da identidade deteriorada. $4^{\text {a }}$ ed. Rio de Janeiro: LTC. (Trabalho original publicado em 1963).

Góis, C. W. L. (2012). Psicologia Clínico Comunitária. Fortaleza: Banco do Nordeste.

Guzzo, R. S. L. (2010). Da opressão à libertação: uma perspectiva urgente para a Psicologia - a conclusão de um projeto, a abertura de perspectivas. In Lacerda Jr. F. e Guzzo, R. S. L. (orgs.) Psicologia \& sociedade: interfaces no debate sobre a questão social (pp. 13-18). Campinas: Alínea.

Haguette, T. M. F. (2005). Metodologias qualitativas na sociologia. Petrópolis: Vozes. (Trabalho original publicado em 1987).

Instituto Brasileiro de Geografia e Estatística. (2010). Censo Demográfico. Brasil: IBGE

Jovchelovitch, S. e Bauer, M. (2002). A Entrevista narrativa. In M. Bauer y W. Gaskell (Eds.), Pesquisa qualitativa com texto, imagem e som: um manual prático (pp. 90-113). Petrópolis: Vozes.

La Taille, Y. (1996). A indisciplina e o sentimento de vergonha. In J. G. Aquino (Ed.), Indisciplina na Escola: alternativas teóricas e práticas (pp. 9-23). São Paulo: Summus.

La Taille, Y. (2002a). Vergonha: a ferida moral. Petrópolis: Vozes.

La Taille, Y. (2002b). O sentimento de vergonha e suas relações com a moralidade. Psicologia: Reflexão e Crítica, 15(1), 13-25. doi: dx.doi.org/10.1590/S0102-79722002000100003

La Taille, Y. (2007). Desenvolvimento humano: contribuições da psicologia moral. Psicologia USP, 18(1), 11-36. doi: 10.1590/ S0103- 6564200700010002

La Taille, Y. (2009). Moralidade e violência: a questão da legitimação de atos violentos. Temas em Psicologia, 17(2), 329-341.

Lukes, S. (1997). Humiliation and the politics of identity. Social Research, 64(1), 36-42.
Marshall, M. N. (1996). Sampling for qualitativa research. Family Practice, 13(6), 522-525.

Mattos, R. M. e Ferreira, R. F. (2004). Quem vocês pensam que (elas) são? Representações sobre as pessoas em situação de rua. Psicologia \& Sociedade, 16(2), 47-58. doi: 10.1590/S010271822004000200007

Mendes, A. G. e Machado, M. F. (2004). Uma clínica para o atendimento a moradores de rua: direitos humanos e composição do sujeito. Psicologia Ciência e Profissão, 24(3), 100-105.

Ministério do Desenvolvimento Social e Combate a Fome. (2009). Rua aprendendo a contar: pesquisa nacional sobre a população em situação de Rua. Brasília: MDS.

Montero, M. (2006). Hacer para transformar: el método en Psicología Comunitaria. Paidós: Buenos Aires.

Moura Jr., J. F. (2012). Reflexões sobre a pobreza a partir da identidade de pessoas em situação de rua de Fortaleza. (Dissertação de Mestrado em Psicologia). Recuperado de: http://www.teses. ufc.br/tde_busca/arquivo.php? $\operatorname{codArquivo}=7161$

Muggleton, T. H. (2013). Public libraries and difficulties with targeting the homeless. Library Review, 62(1/2), 7-18. doi:10.1108/00242531311328113

Prilleltensky, I. (2008). The role of power in wellness, oppression, and liberation the promise of psychopolitical validity. Journal of Community Psychology, 36(2), 116-126. doi: dx.doi. org/10.1002/jcop.20225

Riessman, C. K. (2008). Narrative methods for the Human Sciences. California: Sage.

Rosa, A. S., Secco, M. G. e Brêtas, A. C. P. (2006). O cuidado em situação de rua: revendo o significado do processo de saúdedoença. Revista Brasileira de Enfermagem, 59(3), 331-336. doi: dx.doi.org/10.1590/S0034-71672006000300015

Santos, M. C. L. (2009). Notas sobre a dinâmica socioespacial da população em situação de rua: estratégias de adaptação, sobrevivência e o manejo de recursos disponíveis. In Ministério do Desenvolvimento Social e Combate a Fome. Rua aprendendo a contar: pesquisa nacional sobre a população em situação de rua (pp. 139-156). Brasília: MDS.

Santos, E. S., Koller, S. H., Pilz, C., Dias, D. D. e Wagner, F. (2006). Concepções de policiais sobre crianças em situação de rua: um estudo sobre preconceito. Psico-USF, 11(2), 249-256.

Schick, F. (1997). On humiliation. Social Research, 64(1),131-8.

Silva Filho, D. S. (2002). Feios, sujos e malvados - os "sem-teto" e o mundo do trabalho na Rua. Cadernos de Sociologia e Política, $5,129-151$.

Silveira, F. (2009). Enxergando o invisível: desafios metodológicos de uma (re)construção do olhar. In Ministério do Desenvolvimento Social e Combate a Fome. Rua aprendendo a contar: pesquisa nacional sobre a população em situação de rua. (pp. 41-54). Brasília: MDS. 
Soares, R. G., Nery, F. C., Silveira, P. S., Noto, A. R. e Ronzani, T. M. (2013). Estigma internalizado e auto-estima: uma revisão sistemática da literatura. Revista de Psicologia: Teoria e Prática, 15(4), 116-129.

Sposati, A. (2010). O caminho do reconhecimento dos direitos da população em situação de rua: de indivíduo a população. In Ministério do Desenvolvimento Social e Combate a Fome. Rua aprendendo a contar: pesquisa nacional sobre a população em situação de rua (pp. 193-222). Brasília: MDS.

Veiga, L., Quiroga, J., Novo, M. e Pereira, C. (2009). Trajetória de construção do I Censo e Pesquisa Nacional sobre a População em situação de Rua. In Ministério do Desenvolvimento Social e Combate a Fome. Rua aprendendo a contar: Pesquisa Nacional sobre a população em situação de Rua (pp. 17-40). Brasília: MDS.
Ximenes, V.M. e Barros, J. P. P. (2009). Perspectiva históricocultural: que contribuições teórico-metodológicas podem dar à práxis do psicólogo comunitário? Psicologia Argumento, 27(56), 65-76.

Zavaleta, D. R. (2007).The Ability to go about without shame: a proposal for internationally comparable indicators. Working Paper 03 OPHI .Oxford Poverty y Human Development Initiative, OPHI. Recuperado de http://www.ophi.org.uk/ working-paper-number-03/ 